\title{
Efficacy and tolerability of lumiracoxib, a highly selective cyclo-oxygenase-2 (COX2) inhibitor, in the management of pain and osteoarthritis
}

\author{
Piet Geusens' \\ Willem Lems ${ }^{2}$ \\ 'Department of Internal Medicine, \\ Subdivision of Rheumatology, \\ University Hospital, Maastricht, \\ The Netherlands and Biomedical \\ Research Institute, University Hasselt, \\ Belgium; ${ }^{2}$ Vrije Universiteit Medical \\ Centre, Department of Rheumatology, \\ Amsterdam, the Netherlands
}

\begin{abstract}
Lumiracoxib is a COX2 inhibitor that is highly selective, is more effective than placebo on pain in osteoarthritis (OA), with similar analgesic and anti-inflammatory effects as non-selective NSAIDs and the selective COX2 inhibitor celecoxib, has a lower incidence of upper gastrointestinal (GI) side effects in patients not taking aspirin, and a similar incidence of cardiovascular (CV) side effects compared to naproxen or ibuprofen. In the context of earlier guidelines and taking into account the GI and CV safety results of the TARGET study, lumiracoxib had secured European Medicines Agency (EMEA) approval with as indication symptomatic treatment of OA as well as short-term management of acute pain associated with primary dysmenorrhea and following orthopedic or dental surgery. In the complex clinical context of efficiency and safety of selective and non-selective COX inhibitors, its prescription and use should be based on the risk and safety profile of the patient. In addition, there is further need for long-term GI and CV safety studies and general post-marketing safety on its use in daily practice. Meanwhile, at the time of submission of this manuscript, the EMEA has withdrawn lumiracoxib throughout Europe because of the risk of serious side effects affecting the liver.
\end{abstract}

Keywords: lumiracoxib, NSAIDs, COX2 inhibitors, gastro-intestinal and cardiovascular safety

\section{Introduction}

Non-selective non-steroidal anti-inflammatory drugs (NSAIDs) are widely used by patients with acute pain or with chronic pain due to osteoarthritis (OA) and rheumatoid arthritis (RA) (ACR Recommendations 2000; Hochberg 2002; Jordan et al 2003; Schnitzer 2006). They put them at increased risk for clinically important damage to the mucosa of the upper part of the gastrointestinal tract (Wolfe et al 1999), with a relative risk (RR) of 2.7-5.4 for the so-called PUBs and POBs (PUBs: Perforation, clinically manifest Ulcer and Bleeding; POBs: Perforation, Obstruction, Bleeding) (Hernandez-Diaz and Rodriguez 2000; Ofman et al 2002). OA and RA patients were found to be 2.5-5.5 times more hospitalized for NSAID-related gastro-intestinal (GI) events than the general population (Singh 1988) and 5\%-10\% of PUBs are fatal (Armstrong and Blower 1987).

Cyclo-oxygenase 2 (COX2)-selective inhibitors have been developed based on the finding that the COXs that are constitutively involved in the physiology of the GI mucosa (COX1) are different from the ones that are inducible by inflammation (COX2) (Vane et al 1994; Warner et al 1999; Fitzgerald 2003). Therefore, selective inhibition of COX2 could dissociate anti-inflammatory activity from GI side effects. In this way, COX2 selective inhibitors should reduce clinically manifest ulcers and ulcer complications compared with non-selective NSAIDs, meanwhile exerting similar effects on acute pain 
(eg, primary dysmenorrhea and following orthopedic or dental surgery) and chronic pain in patients with OA or RA.

Preclinical in vitro and animal studies using have been performed proving that COX2 selectivity is a promising approach (Vane et al 1994; Warner et al 1999; Fitzgerald 2003). Several endoscopic studies with selective COX2 inhibitors in humans have shown a reduction of the occurrence of upper GI lesions compared to non-selective NSAIDs (James and Hawkey 2003); moreover, it has been shown that the endoscopic ulcer rate in healthy volunteers or in patients with osteoarthritis was not different between COX2 inhibitorusers and placebo (Laine et al 1999; Rordorf et al 2003a).

However, endoscopic lesions have been considered only as an indicator and surrogate endpoint for clinical upper GI safety (Goldkind 2000). Therefore, clinical trials have been performed to study the effect of selective COX2 inhibitors on clinical relevant upper GI events. Since clinically manifest ulcers and ulcer complications are relatively scarce, very large studies (with a high number of patients) have been performed to show differences in PUBs and POBs.

During the course of emerging studies, it became clear that selective COX2 inhibitors could be associated with an increased incidence of cardiovascular (CV) thrombotic events, including stroke and particularly myocardial infarction (MI), as demonstrated in the VIGOR study, in which the risk of MI was higher in RA-patients treated with rofecoxib than in naproxen users (Bombardier et al 2000). At that time, it was debated whether this difference in $\mathrm{CV}$ risk was the result of a protective effect of naproxen on the incidence of MI (Bombardier et al 2000), or a consequence (side-effect) of the use of COX2 inhibitors.

Later on, in studies developed to observe whether the use of COX2 inhibitors protected against the occurrence of colonic polyps, it has become clear that rofecoxib, as compared to placebo, doubles the risk for thrombotic events, mainly myocardial infarction and ischemic CV events (Bresalier et al 2005; Kerr et al 2007). Also for other COX2 inhibitors, celecoxib and valdecoxib, an elevated CV risk has been shown (Nussmeier et al 2005; Solomon et al 2005).

Although the exact mechanism of this association is still unclear, the balance between prostacyclin ( $\mathrm{PGI}_{2}$ ) and thromboxane $\mathrm{A}_{2}\left(\mathrm{TXA}_{2}\right)$ is presumably shifted to an increased risk for thrombo-embolic events (Fitzgerald 2003). It has been suggested that COX2 is up regulated in vascular segments under conditions of increased vascular shear stress, and that the reduction of endovascular production of prostacyclin by the use of COX2 inhibitors induces an elevated risk of vascular thrombotic events (Solomon 2005).
Besides an elevated $\mathrm{CV}$ risk, it has recently been shown that the use of conventional NSAIDs is associated with edema, congestive heart failure, cardiac arrhythmias, and an increased risk of CV events (Kearney et al 2006; McGettigan and Henry 2006; Vonkemann et al 2006; Zhang et al 2006).

In this context, it was realised that the development of new selective COX2 inhibitors had to be evaluated in a much broader context of safety than only GI protection and had to include data on CV safety (Silverstein et al 2000; Farkouh et al 2004; Schnitzer et al 2004; Cannon et al 2006; Laine et al 2007). In order to perform such studies, larger trials were needed with more endpoints than in the original studies that focused on GI protection only. In addition, also for the non-selective NSAIDs additional data were required to adequately judge their effect on $\mathrm{CV}$ risk.

Several clinical trials have been performed to study both the GI and CV safety with COX2 (Tables 1-4), including VIGOR (rofecoxib vs naproxen) (Bombardier et al 2000), CLASS (celecoxib vs diclofenac and ibuprofen) (Silverstein et al 2000), MEDAL (etoricoxib vs diclofenac in a pooled analysis) (Cannon et al 2006; Laine et al 2007), and TARGET (lumiracoxib vs ibuprofen and naproxen) (Farkouh et al 2004; Schnitzer et al 2004), which will be discussed in detail later in this review.

These studies differed between each other in many aspects. Differences included indications for treatment (OA and/or RA), number of patients included (between 8059 and 37,701 ), the comparator non-selective NSAIDs (naproxen, diclofenac, ibuprofen; none was placebo-controlled), duration of the study (6-36 months), exclusion or not because of history of GI risks/events (GI surgery, current bleeding, active GI disorder, recent ulcer, intake of GI protectors, bleeding last year, any perforation, obstruction or not), GI protection during the study (not allowed, allowed, stimulated in high risk patients), definitions of upper GI side effect endpoints (various combinations of PUBOs, eventually further specified as complicated or not), exclusion or not because of history of CV risks/events (during variable time periods before the study (during last 6 months to ever), and defined as any CV event or specified as MI (clinical or on ECG), coronary bypass, percutaneous coronary intervention, stroke, new angina, low dose aspirin (allowed, stimulated, or not allowed), severe heart failure), and definitions of CV side effect endpoints (MI alone, composite endpoints including variable combinations of MI, stroke, angina, any or arterial thrombotic events, or including more standardized outcomes from the Anti-Platelet Trialists' Collaboration endpoint). 
Table I General description of main large-scale safety trials with selective COX2 inhibitors and description of patients excluded from participating in the studies

\begin{tabular}{|c|c|c|c|c|c|c|}
\hline Drug (reference) & Study & $\begin{array}{l}\text { Diagnoses and } \\
\text { patients }(n)\end{array}$ & $\begin{array}{l}\text { Duration } \\
\text { (months) }\end{array}$ & $\begin{array}{l}\text { Comparator } \\
\text { drug }\end{array}$ & $\begin{array}{l}\text { Risk patients excluded } \\
\text { GI history }\end{array}$ & CV history \\
\hline $\begin{array}{l}\text { Rofecoxib } \\
\text { (Bombardier 2000) }\end{array}$ & VIGOR & RA (8 076) & 12 & Naproxen & $\begin{array}{l}\text { Gl surgery, current } B, I B D \text {, } \\
\text { previous or current PPI }\end{array}$ & $\begin{array}{l}\text { History of } \mathrm{CV} \text { last } 2 \mathrm{yrs}, \mathrm{Ml} \text { or } \\
\text { coronary bypass last } \mathrm{yr} \text {, previous } \\
\text { or current aspirin }\end{array}$ \\
\hline $\begin{array}{l}\text { Celecoxib } \\
\text { (Silverstein 2000) }\end{array}$ & CLASS & OA, RA (8 059) & 6 & $\begin{array}{l}\text { Ibuprofen, } \\
\text { diclofenacv }\end{array}$ & $\begin{array}{l}\text { Active } \mathrm{Gl}, \mathrm{U} \text { last } 30 \mathrm{~d} \text {, any } \\
\mathrm{Gl} \text { surgery }\end{array}$ & No exclusion criteria \\
\hline $\begin{array}{l}\text { Etoricoxib } \\
\text { (Cannon 2006; } \\
\text { Laine 2007) }\end{array}$ & MEDAL & OA, RA (37 70I) & 36 & Diclofenac & $\begin{array}{l}\text { No exclusion } \\
\text { PPI or misoprostol rec- } \\
\text { ommended if at Gl risk }\end{array}$ & $\begin{array}{l}\text { MI or coronary bypass or } \\
\text { percutaneous coronary } \\
\text { intervention during last } 6 \mathrm{mo} \text {, } \\
\text { aspirin recommended if at } \mathrm{CV} \text { risk }\end{array}$ \\
\hline $\begin{array}{l}\text { Lumiracoxib } \\
\text { (Schnitzer 2004; } \\
\text { Farkouh 2004) }\end{array}$ & TARGET & OA (l8 325) & 12 & $\begin{array}{l}\text { lbuprofen, } \\
\text { naproxen }\end{array}$ & $\begin{array}{l}\text { On GI protection, } \mathrm{U} \text { last } \\
3 \text { mo, } \mathrm{B} \text { last } \mathrm{yr} \text {, any } \mathrm{P} \text { or } \mathrm{O}\end{array}$ & $\begin{array}{l}\text { MI (clinical, on ECG), stroke, } \\
\text { coronary bypass graft surgery, } \\
\text { new angina during last } 6 \text { mo, high } \\
\text { CV risk without aspirin, severe } \\
\text { heart failure, on anticoagulation } \\
\text { therapy }\end{array}$ \\
\hline
\end{tabular}

Abbreviations: B, bleeding; CV, cardiovascular; GI, gastrointestinal; IBD, inflammatory bowel disease; MI, myocardial infarction; O, obstruction; OA, osteoarthritis; P, perforation; $\mathrm{RA}$, rheumatoid arthritis; $\mathrm{PPI}$, proton pump inhibitors; $\mathrm{U}$, ulcer.

In these studies, rofecoxib and etoricoxib decreased the risk of GI event endpoints (Table 2), but the size and significance of effects according to definitions of GI events and reporting on significance of interaction of treatment-by-subgroup analysis differed between the drugs (Bombardier et al 2000; Silverstein et al 2000; Cannon et al 2006; Laine et al 2007). Celecoxib did not decrease the primary GI endpointv (POBs) over the entire duration of the study, but significantly reduced the risk of GI events when symptomatic ulcers were included in the analysis (Silverstein et al 2000).

In these studies, rofecoxib increased the risk of MI (HR: 4.25, CI: 1.39-17.37) (Bombardier et al 2000), which was the reason for withdrawal of rofecoxib $\left(\operatorname{Vioxx}^{\circledR}\right)$ from the market in September 2004. Low dose celecoxib and etoricoxib did not affect the risk of pre-specified composite $\mathrm{CV}$ endpoints in the total group of patients and in specified subgroups (on low dose aspirin or not) as compared to their comparator non-selective NSAID(s) (Table 3) (Silverstein et al 2000; Cannon et al 2006; Laine et al 2007).

It is important to realize that the similarity of incidence of $\mathrm{CV}$ risk between selective and non-selective $\mathrm{COX}$ inhibitors does not mean that there is no increased $\mathrm{CV}$ risk of selective COX2 inhibitors compared to placebo. On the contrary, compared to placebo, it has been demonstrated that the selective COX2 inhibitors rofecoxib (Bresalier et al 2005; Kerr et al 2007) and celecoxib (Solomon et al 2005) at high doses increase the risk of $\mathrm{CV}$ events compared to placebo. Furthermore, non-selective NSAIDs, such as ibuprofen (Antman et al 2007), diclofenac (Antman et al 2007), but probably not naproxen (Antman et al 2007) and even paracetamol (Chan et al 2006), were associated with an increased risk for CV events compared to placebo in meta-analyses.

In this complex safety context, we review here the data on the effects and safety of lumiracoxib, a highly selective COX2 inhibitor.

\section{Lumiracoxib Preclinical data}

Lumiracoxib (Prexige ${ }^{\circledR}$ ) is a selective COX2 inhibitor developed for the treatment of osteoarthritis, rheumatoid arthritis, and acute pain (Lyseng-Williamson and Curran 2004; Esser et al 2005).

Lumiracoxib differs structurally from other drugs in the class of selective COX2 inhibitors (Brune and Hinz 2004; Mangold et al 2004). The other inhibitors contain a tricyclic ring and a sulfone or sulfonamide group (Brune and Hinz 2004) whereas lumiracoxib is a phenyl acetic acid derivative. It has the highest selectivity (selective for COX2 compared with COX1 in the human whole blood assay with a ratio of 515:1 in healthy subjects and in patients with osteoarthritis or rheumatoid arthritis) and a fairly short plasma half-life (3-6 hours) compared with other COX2-selective inhibitors (Esser et al 2005).

Lumiracoxib has good oral bioavailability (74\%). It is rapidly absorbed, reaching maximum plasma concentrations 2 hours after dosing, and is highly plasma protein bound. Lumiracoxib has a short elimination half-life from plasma (mean 4 hours) and demonstrates dose-proportional plasma 
Table 2 Gastrointestinal endpoints in studies of selective COX2 inhibitors

\begin{tabular}{|c|c|c|c|c|c|c|c|}
\hline \multirow[t]{2}{*}{$\begin{array}{l}\text { Drug } \\
\text { (reference) }\end{array}$} & \multirow[t]{2}{*}{ Study } & \multirow[t]{2}{*}{$\begin{array}{l}\text { GI protection } \\
\text { allowed in study }\end{array}$} & \multicolumn{2}{|l|}{ GI endpoints } & \multicolumn{3}{|c|}{$\begin{array}{l}\text { Hazard ratios, relative risks (RR) or incidence (\%) of } \\
\text { upper GI risk endpoints }\end{array}$} \\
\hline & & & & & All & No aspirin & On aspirin \\
\hline Rofecoxib & VIGOR & Yes & Confirmed POBU & & $0.5(0.3-0.6) v$ & Idem & Excluded \\
\hline $\begin{array}{l}\text { (Bombardier } \\
\text { 2000) }\end{array}$ & & & $\begin{array}{l}\text { Complicated Gl } \\
\text { (POB) }\end{array}$ & & $0.4(0.2-0.8)$ & Idem & Excluded \\
\hline Celecoxib & CLASS & No & POB & & RR: $0.53(0.26-I . I I)$ & RR: $0.35(0.14-0.98)$ & $1.0 \%$ vs $2.1, \mathrm{NS}$ \\
\hline $\begin{array}{l}\text { (Silverstein } \\
2000)\end{array}$ & & & $\begin{array}{l}\text { Symptomatic } U+ \\
\text { POB }\end{array}$ & & RR: $0.59(0.38-0.94)$ & RR: $0.48(0.28-0.89)$ & $4.7 \%$ vs $6.0 \%$, NS \\
\hline \multirow{9}{*}{$\begin{array}{l}\text { Etoricoxib } \\
\text { (Cannon 2006; } \\
\text { Laine 2007) }\end{array}$} & MEDAL & Yes & Clinical POBU & All & $0.69(0.57-0.83)$ & $0.60(0.45-0.80)$ & $0.78(0.60-1.0 \mathrm{I})$ \\
\hline & & & & No PPI & $0.62(0.45-0.83)$ & $0.60(0.43-0.86)$ & $0.93(0.65-1.35)$ \\
\hline & & & & $+\mathrm{PPI}$ & $0.74(0.58-0.95)$ & $0.59(0.36-0.98)$ & $0.64(0.44-0.93)$ \\
\hline & & & $\begin{array}{l}\text { Complicated GI } \\
(\mathrm{POB})^{\mathrm{a}}\end{array}$ & All & $0.91(0.67-1.24)$ & $0.90(0.53-1.50)$ & $0.93(0.63-1.36)$ \\
\hline & & & & No PPI & $1.03(0.70-1.52)$ & $0.96(0.52-1.79)$ & $1.09(0.66-1.77)$ \\
\hline & & & & $+\mathrm{PPI}$ & $0.72(0.42-1.22)$ & $0.77(0.30-1.95)$ & $0.70(0.37-1.34)$ \\
\hline & & & Uncomplicated Ua & All & $0.57(0.45-0.74)$ & $0.50(0.35-0.7 \mathrm{I})$ & $0.67(0.47-0.96)$ \\
\hline & & & & No PPI & $0.58(0.4 I-0.8 I)$ & $0.49(0.32-0.75)$ & $0.77(0.44-1.34)$ \\
\hline & & & & $+\mathrm{PPI}$ & $0.57(0.39-0.83)$ & $0.53(0.29-0.98)$ & $0.61(0.38-0.97)$ \\
\hline \multirow{4}{*}{$\begin{array}{l}\text { Lumiracoxib } \\
\text { (Schnitzer 2004; } \\
\text { Farkouh 2004) }\end{array}$} & TARGET & No & $\begin{array}{l}\text { Definite or probabl } \\
\cup(P O B)\end{array}$ & e complicated & & & \\
\hline & & & & $\begin{array}{l}\text { vs ibuprofen }+ \\
\text { naproxen }\end{array}$ & $0.34(0.22-0.52)$ & $0.21(0.12-0.37)$ & $0.79(0.40-1.55)$ \\
\hline & & & & vs ibuprofen & $0.29(0.14-0.59)$ & $0.17(0.07-0.45)$ & $0.92(0.27-3.20)$ \\
\hline & & & & vs naproxen & $0.37(0.22-0.63)$ & $0.24(0.12-0.50)$ & $0.73(0.32-1.65)$ \\
\hline
\end{tabular}

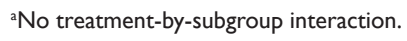

Abbreviations: $\mathrm{B}$, bleeding; $\mathrm{Gl}$, gastrointestinal; O, obstruction; P, perforation; PPI, proton pump inhibitors; $\mathrm{U}$, ulcer.

pharmacokinetics with no accumulation during multiple dosing.

Lumiracoxib is metabolized extensively prior to excretion, with only a small amount excreted unchanged in urine or feces. Lumiracoxib and its metabolites are excreted via renal and fecal routes in approximately equal amounts (LysengWilliamson and Curran 2004).

Lumiracoxib does not exhibit any clinically meaningful interactions with a range of commonly used medications including aspirin (acetylsalicylic acid), fluconazole, an ethinylestradiol- and levonorgestrel-containing oral contraceptive, omeprazole, the antacid Maalox ${ }^{\circledR}$, methotrexate, and warfarin (although, as in common practice, routine monitoring of coagulation is recommended when lumiracoxib is co-administered with warfarin) (Lyseng-Williamson and Curran 2004).

\section{Clinical efficacy}

The effectiveness of lumiracoxib was superior to placebo in patients with $\mathrm{OA}$ at doses of $100 \mathrm{mg}$ and $200 \mathrm{mg}$ once daily and similar to celecoxib and non-selective NSAID, as described and reviewed in detail in Lyseng-Williamson and Curran (2004).
Several studies have been shown the superiority of lumiracoxib compared to placebo in pain in RA (Guesens et al 2004), after surgery, orthopedic surgery, primary dysmenorrhea and tension headache (Lyseng-Williamson and Curran 2004).

\section{Safety}

Upper gastrointestinal safety: endoscopic studies

In endoscopic studies, lumiracoxib has been associated with a rate of acute gastric injury and chronic ulcer formation that does not differ from placebo (Rordorf et al 2003b) and which was significantly lower than with the non-selective NSAID ibuprofen and with celecoxib (Hawkey et al 2004;

Kivitz et al 2004).

\section{Clinical gastrointestinal safety}

To establish the gastrointestinal safety of lumiracoxib, the Therapeutic Arthritis Research and Gastrointestinal Event Trial (TARGET) was performed to test the hypothesis that patients with osteoarthritis, randomized to lumiracoxib (400 mg once daily, which is $2-4$ times the recommended dose for osteoarthritis), had significantly fewer complicated ulcers than patients randomized to either ibuprofen 
Table 3 Cardiovascular endpoints in studies of selective COX2 inhibitors

\begin{tabular}{|c|c|c|c|c|c|c|}
\hline \multirow[t]{2}{*}{ Drug (reference) } & \multirow[t]{2}{*}{ Study } & \multirow{2}{*}{$\begin{array}{l}\text { Aspirin } \\
\text { allowed }\end{array}$} & \multirow[t]{2}{*}{ CV endpoints } & \multicolumn{3}{|c|}{ Hazard ratios or incidence of $\mathrm{CV}$ endpoints } \\
\hline & & & & All & No aspirin & On aspirin \\
\hline Rofecoxib & VIGOR & No & MI & $4.25(1.39-17.37)$ & Idem & Excluded \\
\hline (Bombardier 2000) & & & CV death & $0.2 \%$ vs $0.2 \%$, NS & Idem & Excluded \\
\hline $\begin{array}{l}\text { Celecoxib } \\
\text { (Silverstein 2000) }\end{array}$ & CLASS & Yes & Ml, stroke or angina & $0.9 \%$ vs $1.0 \%$, NS & $0.5 \%$ vs $0.4 \%$, NS & $\mathrm{nr}$ \\
\hline Etoricoxib (Cannon & MEDAL & Stimulated & ${ }^{\mathrm{a}}$ Any thrombotic events & $0.95(0.8 \mathrm{I}-\mathrm{I} . \mathrm{II})$ & d $\mathrm{l} .0 \%$ vs $1.0 \%$, NS & ${ }^{\mathrm{d}} .67 \%$ vs $1.87 \%$, NS \\
\hline \multirow[t]{2}{*}{ 2006; Laine 2007) } & & & ${ }^{\mathrm{a}}$ Arterial thrombotic events & $0.96(0.8 I-I . I 3)$ & $\mathrm{nr}$ & $\mathrm{nr}$ \\
\hline & & & a,bAPTC (all MI, stroke or vascular death) & $0.96(0.79-1.16)$ & $\mathrm{nr}$ & $\mathrm{nr}$ \\
\hline Lumiracoxib & TARGET & Yes & bAPTC (all MI, stroke or vascular death) & & & \\
\hline (Schnitzer 2004; & & & vs ibuprofen + naproxen & $1.14(0.78-1.66)$ & $1.22(0.74-2.02)$ & $1.04(0.59-1.84)$ \\
\hline \multirow[t]{6}{*}{ Farkouh 2004) } & & & vs ibuprofen & $0.76(0.4 I-1.40)$ & $0.94(0.44-2.04)$ & $0.56(0.20-1.54)$ \\
\hline & & & vs naproxen & $1.46(0.89-2.37)$ & $1.49(0.76-2.92)$ & $1.42(0.70-2.90)$ \\
\hline & & & $\begin{array}{l}\text { Confirmed or probable MI (clinical and } \\
\text { silent) }\end{array}$ & & & \\
\hline & & & vs ibuprofen + naproxen & $1.31(0.70-2.45)$ & $1.47(0.63-3.39)$ & I. $14(0.44-2.95)$ \\
\hline & & & vs ibuprofen & $0.66(0.2 I-2.09)$ & $0.75(0.20-2.79)$ & $0.47(0.04-5.14)$ \\
\hline & & & vs naproxen & $1.77(0.82-3.84)$ & $2.37(0.74-7.55)$ & $1.36(0.47-3.93)$ \\
\hline
\end{tabular}

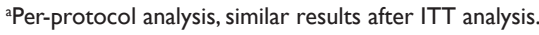

'APTC, Anti-Platelet Trialists' Collaboration endpoint.

incidence.

devents per 100 patient yrs.

Abbreviation: nr, not reported.

$(3 \times 800 \mathrm{mg} /$ day $)$ or naproxen $(2 \times 500 \mathrm{mg} /$ day $)$, without affecting CV risk (Farkouh et al 2004; Schnitzer et al 2004). To address these issues, TARGET $(\mathrm{n}=18,325)$ was, by design, much larger than CLASS $(n=8059)$ and VIGOR ( $\mathrm{n}=8$ 076) outcome trials, but smaller than the pooled analysis in MEDAL $(\mathrm{n}=37,701)$.

The TARGET trial included patients with clinical OA of hip, knee or hands, or with radiographic OA of the spine (without of radicular symptoms). Based on the GI risk profile at baseline, patients were excluded if they were on GI protection, had an upper GI ulcer during the last 3 months, GI bleeding last year or any history of perforation or obstruction (Table 1) (Schnitzer et al 2004). Lumiracoxib showed, in the total group, a 3- to 4-fold reduction in upper GI ulcer complications (POBs) compared both comparators combined (RR: 0.34, CI: 0.22-0.52) and either naproxen or ibuprofen (Table 2). Remarkably, the relative risk reduction for lumiracoxib (0.34) seems at first sight to be larger than for rofecoxib, celecoxib, and etoricoxib. However, this comparison is difficult, if not impossible to interpret, since it is not based on a head to head comparison, and the inclusion and exclusion criteria and definition of endpoints of these studies were different. This effect was found in patients not taking low dose aspirin (RR: 0.21, CI: 0.12-0.37), but was not significant in those taking low dose aspirin (RR: 0.79, CI: 0.40-1.55).

\section{Clinical cardiovascular safety}

Based on CV risk profile at baseline, patients were excluded from the TARGET study if they had a history of MI (clinical or silent as shown on ECG), stroke, coronary bypass, new angina of recent onset (last 6 months), high CV risk without intake of aspirin or severe heart failure (Farkouh et al 2004). The primary composite endpoint (the incidence of MI, stroke, and $\mathrm{CV}$ death) did not differ between lumiracoxib and ibuprofen or naproxen combined (RR: 1.14, CI: 0.78-1.66) or separately, irrespective of aspirin use (RR: 1.22 and 1.04). Thus, the overall CV signal showed no difference but this is because the study is underpowered to demonstrate statistically significant and clinically meaningful differences. There was a trend towards more $\mathrm{CV}$ events relative to naproxen (RR: 1.46, CI: 0.89-2.37) and fewer events relative to ibuprofen (RR: 0.76, CI: 0.41-1.40).

It is important to realize that the TARGET trial has been performed in patients with a relatively low risk for $\mathrm{CV}$ events. Patients were excluded from the study if they had a MI, stroke, coronary artery bypass graft surgery, percutaneous coronary intervention or new-onset angina within 6 months prior to screening, electrocardiogram (ECG) evidence of silent myocardial ischemia, New York Heart Association congestive heart failure class III-IV, or if they were receiving anticoagulation therapy. As a consequence, it cannot be fully excluded that a difference between the comparators 
would have been observed if more high risk patients would have been enrolled.

The incidence of composite GI and CV endpoints combined fell by $35 \%$ in patients treated with lumiracoxib compared to both comparators (RR: 0.65 , CI: $0.49-0.84$ ), by $50 \%$ compared to ibuprofen $(\mathrm{p}<0.01)$ and by $25 \%$ compared to naproxen (NS).

\section{Other safety data}

Non-selective NSAIDs interfere with COX1 and COX2 in the kidney (Harris 2006). Their most common renal side effect is peripheral edema due to increased sodium retention (Harris 2006), which also is one of the contributors to an increase in blood pressure. Acute renal failure is a rare but potentially serious complication of non-selective NSAIDs (Harris 2006), which predominantly occurs in elderly with cardiovascular involvement during periods of dehydration (diarrhea, high fever). Also selective COX2 inhibitors may cause edema, congestive heart failure and modest elevations of blood pressure (Harris 2006). In the MEDAL study, more discontinuations were observed in etoricoxib users due to hypertension and edema than in diclofenac users (no difference was found for congestive heart failure) (Cannon et al 2006; Laine et al 2007).

In the TARGET study (Farkouh et al 2004; Schnitzer et al 2004), the incidence of major renal events and chronic heart failure were similar between the treatment groups (Table 4), while unfortunately the incidence of peripheral edema was not reported. Interestingly, blood pressure remained stable in patients treated with lumiracoxib, which was significantly different from the moderate but significant increase in blood pressure with naproxen and diclofenac. In the TARGET study no data were presented on cutaneous side effects (Farkouh et al 2004; Schnitzer et al 2004).

Hepatotoxicity has been the reason for withdrawal of some NSAIDs from the market, but symptomatic hepatic effects attributable to NSAIDs are rare and usually mild (Bannwarth and Berenbaum 2005). Lumiracoxib has a molecular phenyl acetic acid structure that is similar to that of diclofenac, the most widely prescribed NSAID world-wide, probably with an elevated risk for hepatotoxicity (which is estimated to occur in $4 \%$ of all patients). In the TARGET study the incidence of serious liver abnormalities (not further specified in the manuscript) was similar between the treatment groups, but lumiracoxib was associated with a RR of 3.97 (CI: 2.96-5.32) for increase in liver tests above 3 times the upper normal limit (Farkouh et al 2004; Schnitzer et al 2004). Thus, the risk of hepatotoxicity with the use of lumiracoxib is higher than for naproxen and ibuprofen. At the time of first submission of this manuscript, lumiracoxib was withdrawn from the market in Australia (where it had been on the market for several years and prescribed to 60,000 patients in doses up to $400 \mathrm{mg}$ /day) because of 8 reports of serious liver adverse reactions to the drug, including 2 deaths and 2 liver transplants, further details of which were not yet available. Meanwhile, due to these serious liver adverse affects at doses $>100 \mathrm{mg} /$ day, lumiracoxib was withdrawn from the market in several countries, including the UK and Germany. In this context lumiracoxib should, were available, be limited to the lowest effective dose for the shortest possible duration of treatment. The reader is advised to inspect the safety issues that

Table 4 Incidence of other side effects in studies of selective COX2 inhibitors

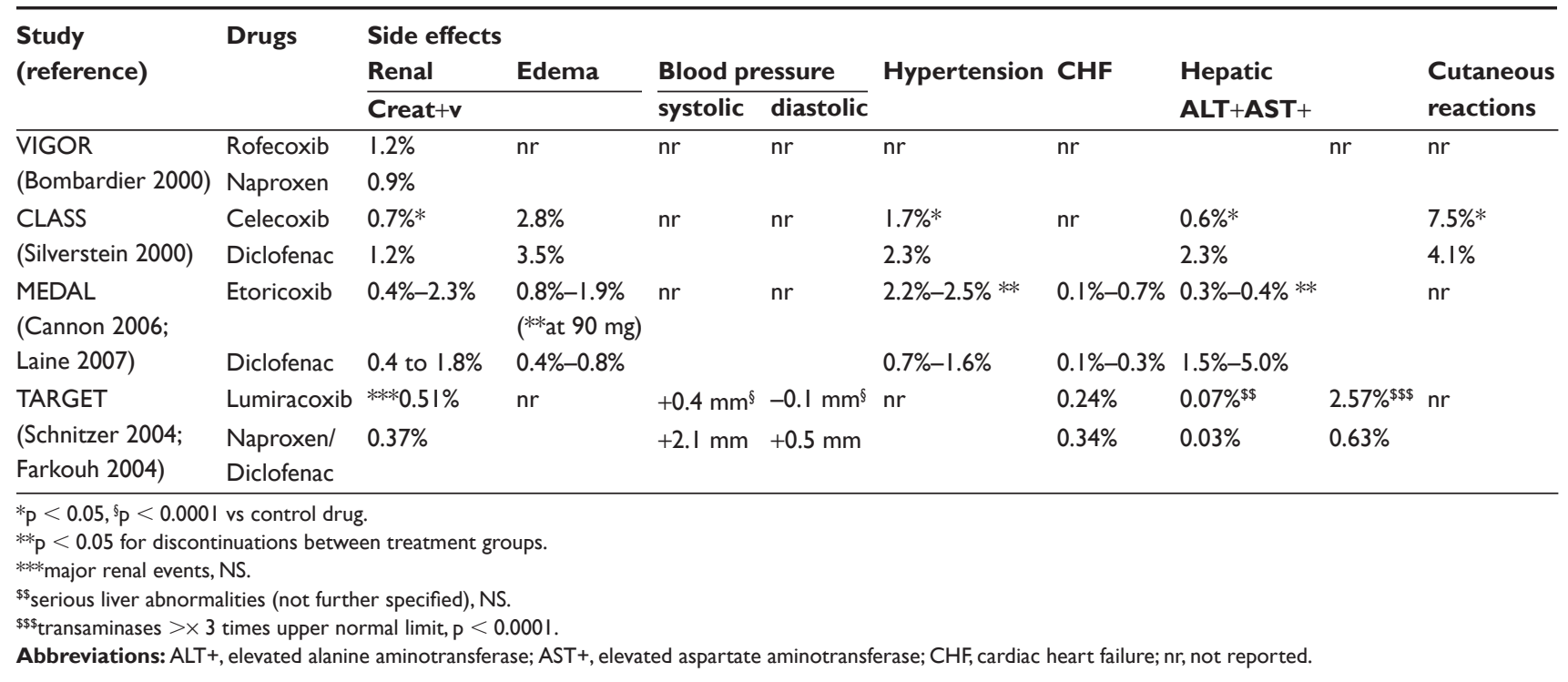


Table 5 Proposed indications for the use of selective COX2 and non-selective NSAIDs according to Gl and CV risk (Chan 2006)

\begin{tabular}{llll}
\hline CV risk & GI risk $^{\mathbf{a}}$ & & \\
\cline { 2 - 4 } & Low & Moderate & High \\
\hline Low & NSAID & NSAID + PPI/misoprostol or COX2 inhibitor & COX2 inhibitor + PPI \\
High $^{b}$ & NSAID $^{c}+$ PPI or misoprostol & NSAID $^{c}+$ PPI or misoprostol & Avoid NSAIDs or COX2 inhibitor $^{d}$ \\
\hline
\end{tabular}

${ }^{a}$ Gastrointestinal risk is arbitrarily defined as low (no risk factors), moderate (presence one or two risk factors), or high (more than two risk factors, previous ulcer complications, or concomitant use of corticosteroids or anticoagulants). All patients with a history of ulcers who require NSAIDs should be tested for $H$. pylori and if infection is present, eradication therapy should be given.

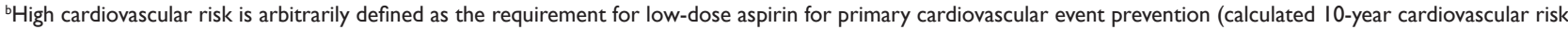

$>10 \%$ ) or secondary prevention of serious cardiovascular events.

'Naproxen is the preferred NSAID in patients with a high cardiovascular risk.

dbuprofen should be avoided with aspirin (Farkouh et al 2007).

Abbreviation: PPI, proton pump inhibitors.

are emerging about liver safety, including baseline evaluation of history of liver diseases and regular checking liver function during treatment, and instructions about follow-up of liver function tests during treatment.

\section{Conclusions}

Lumiracoxib is a COX2 inhibitor that is highly selective, is more effective than placebo on pain in OA, with similar analgesic and anti-inflammatory effects as non-selective NSAIDs and the selective COX2 inhibitor celecoxib, has a lower incidence of upper GI side effects in patients not taking aspirin and a similar incidence of $\mathrm{CV}$ side effects as compared to naproxen or ibuprofen.

In the context of earlier guidelines (ACR Recommendations 2000; Hochberg 2002; Jordan et al 2003; Schnitzer 2006) and taking into account the GI and CV safety results of the TARGET study (Farkouh et al 2004; Schnitzer et al 2004), lumiracoxib is strictu sensu indicated in the treatment of patients with clinical OA of hip, knee or hands, or with radiographic OA of the spine, who do not respond to conventional treatment (such as analgesics [acetaminophen], physical therapy, and weight reduction in case of hip and knee OA), who have a moderate or high GI risk (with the restriction that in the TARGET study patients with a recent ulcer or bleeding or any history of perforation or obstruction were excluded) and a low CV risk and are not taking low dose aspirin (Table 5) (Chan 2006).

Lumiracoxib has been secured EMEA approval under the name of Prexige ${ }^{\mathrm{TM}}$ and Prexigen ${ }^{\mathrm{TM}}$ and has been launched in the UK since January 2006, where it is indicated for symptomatic treatment of osteoarthritis as well as shortterm management of acute pain associated with primary dysmenorrhea and following orthopedic or dental surgery (www.emea.eu). The UK acted as the reference state in the EU's mutual recognition procedure.

In the complex clinical context of efficiency and safety of selective and non-selective COX inhibitors, the prescription and use of COX2 inhibitors should be based on the risk and safety profile of the patient. One example is given in Table 5, in which the use of selective COX2 is proposed to be limited to patients with a low $\mathrm{CV}$ risk together with a moderate or high GI risk (Chan 2006). In addition, there is further need for long-term GI and CV safety studies on the use of selective and non-selective COX inhibitors. In view of the liver adverse effects, lumiracoxib should be limited to the lowest effective dose for the shortest possible duration of treatment, with special attention for liver toxicity according to the upcoming safety instructions. However, at the time of submission, lumiracoxib had been withdrawn from the market in several countries, including the UK and Germany, because of liver side effects at doses $>100 \mathrm{mg} /$ day. Meanwhile, at the time of proof approval of this paper, the European Medicines Agency (EMEA) had completed a review of the safety of medicines containing lumiracoxib. The Agency's Committee for Medicinal Products for Human Use (CHMP) concluded that the benefits of these medicines no longer outweigh their risks, and that all marketing authorizations should be withdrawn throughout Europe because of the risk of serious side effects affecting the liver (www.emea.europa.eu).

\section{References}

[ARC Recommendations] Recommendations for the medical management of osteoarthritis of the hip and knee: 2000 update. 2000. American College of Rheumatology Subcommittee on Osteoarthritis Guidelines. Arthritis Rheum, 43:1905-15.

Antman EM, Bennett JS, Daugherty A, et al; American Heart Association. 2007. Use of nonsteroidal antiinflammatory drugs: an update for clinicians: a scientific statement from the American Heart Association. Circulation, 115:1634-42.

Armstrong CP, Blower AL. 1987. Non-steroidal anti-inflammatory drugs and life threatening complications of peptic ulceration. Gut, 28:527-32.

Bannwarth B, Berenbaum F. 2005. Clinical pharmacology of lumiracoxib, a second-generation cyclooxygenase 2 selective inhibitor. Expert Opin Investig Drugs, 14:521-33.

Bombardier C, Laine L, Reicin A, et al; VIGOR Study Group. 2000. Comparison of upper gastrointestinal toxicity of rofecoxib and naproxen in patients with rheumatoid arthritis. VIGOR Study Group. $N$ Engl $J$ Med, 343:1520-8. 
Bresalier RS, Sandler RS, Quan H, et al; Adenomatous Polyp Prevention on Vioxx (APPROVe) Trial Investigators. 2005. Cardiovascular events associated with rofecoxib in a colorectal adenoma chemoprevention trial. N Engl J Med, 352:1092-102.

Brune K, Hinz B. 2004. Selective cyclooxygenase-2 inhibitors: similarities and differences. Scand J Rheumatol, 33:1-6.

Cannon CP, Curtis SP, FitzGerald GA, et al; MEDAL Steering Committee. 2006.Cardiovascular outcomes with etoricoxib and diclofenac in patients with osteoarthritis and rheumatoid arthritis in the Multinational Etoricoxib and Diclofenac Arthritis Long-term (MEDAL) programme: a randomised comparison. Lancet, 368:1771-81.

Chan AT, Manson JE, Albert CM, et al. 2006. Nonsteroidal antiinflammatory drugs, acetaminophen, and the risk of cardiovascular events. Circulation, 113:1578-87.

Chan FK. 2006. Primer: managing NSAID-induced ulcer complications balancing gastrointestinal and cardiovascular risks. Nat Clin Pract Gastroenterol Hepatol, 3:563-73.

Esser R, Berry C, Du Z, et al. 2005. Preclinical pharmacology of lumiracoxib: a novel selective inhibitor of cyclooxygenase-2. Br J Pharmacol, 144:538-50.

Farkouh ME, Greenberg JD, Jeger RV, et al. 2007. Cardiovascular outcomes in high risk patients with osteoarthritis treated with ibuprofen, naproxen or lumiracoxib. Ann Rheum Dis, 66:764-70.

Farkouh ME, Kirshner H, Harrington RA, et al; TARGET Study Group. 2004. Comparison of lumiracoxib with naproxen and ibuprofen in the Therapeutic Arthritis Research and Gastrointestinal Event Trial (TARGET), cardiovascular outcomes: randomised controlled trial. Lancet, 364:675-84.

Fitzgerald GA. 2003. COX-2 and beyond. Nature Rev Drug Discov, 879.

Geusens P, Alten R, Rovensky J, et al. 2004. Efficacy, safety and tolerability of lumiracoxib in patients with rheumatoid arthritis. Int $J$ Clin Pract, 58:1033-41.

Goldkind L. 2000. Medical officer's gastroenterology advisory committee briefing document. Division of anti-inflammatory, analgesic and ophthalmologic drug products: HFP-550. 12 Jun 2000 [online]. Accessed 22 March 2006. URL: www.fda.gov/ohrms/dockets/ac/01/ briefing/3677b1_05_gi.doc.

Harris RC. 2006. COX-2 and the kidney. J Cardiovasc Pharmacol, 47(Suppl 1):S37-42.

Hawkey CJ, Svoboda P, Fiedorowicz-Fabrycy IF, et al. 2004. Gastroduodenal safety and tolerability of lumiracoxib compared with ibuprofen and celecoxib in patients with osteoarthritis. J Rheum, 31:1804-10

Hernandez-Diaz S, Rodriguez LA. 2000. Association between nonsteroidal anti-inflammatory drugs and upper gastrointestinal tract bleeding/perforation: an overview of epidemiologic studies published in the 1990s. Arch Intern Med, 160:2093-9.

Hochberg MC. 2002. New directions in symptomatic therapy for patients with osteoarthritis and rheumatoid arthritis. Semin Arthritis Rheum, 32(Suppl 1):4-14.

James MW, Hawkey CJ. 2003. Assessment of non-steroidal antiinflammatory drug (NSAID) damage in the human gastrointestinal tract. Br J Clin Pharmacol, 56:146-55.

Jordan KM, Arden NK, Doherty M, et al; Standing Committee for International Clinical Studies Including Therapeutic Trials ESCISIT. 2003. EULAR Recommendations 2003: an evidence based approach to the management of knee osteoarthritis: Report of a Task Force of the Standing Committee for International Clinical Studies Including Therapeutic Trials (ESCISIT). Ann Rheum Dis, 62:1145-55.

Kearney PM, Baigent C, Godwin J, et al. 2006. Do selective cyclooxygenase inhibitors and traditional non steroidal drugs increase the risk of athero-thrombosis? Meta-analysis of randomised trials. $B M J, 332: 1302-5$.

Kerr DJ, Dunn JA, Langman MJ, et al; VICTOR Trial Group. 2007. Rofecoxib and cardiovascular adverse events in adjuvant treatment of colorectal cancer. $N$ Engl J Med, 357:360-9.
Kivitz AJ, Nayiager S, Schimansky T, et al. 2004. Reduced incidence of gastroduodenal ulcers associated with lumiracoxib compared with ibuprofen in patients with rheumatoid arthritis. Aliment Pharmacol Ther, 19:1189-98.

Laine L, Curtis SP, Cryer B, et al; MEDAL Steering Committee. 2007. Assessment of upper gastrointestinal safety of etoricoxib and diclofenac in patients with osteoarthritis and rheumatoid arthritis in the Multinational Etoricoxib and Diclofenac Arthritis Long-term (MEDAL) programme: a randomized comparison. Lancet, 369:465-73.

Laine L, Harper S, Simon T, et al. 1999. A randomized trial comparing the effect of rofecoxib, a cyclo-oxygenase 2 specific inhibitor, with that of ibuprofen on the gastroduodenal mucosa of patients with osteoarthritis. Gastroenterology, 117:776-83.

Lyseng-Williamson KA, Curran MP. 2004. Lumiracoxib. Drugs, 64:2237-46

Mangold JB, Gu H, Rodriguez LC, et al. 2004. Pharmacokinetics and metabolism of lumiracoxib in healthy male subjects. Drug Metab Dispos, 32:566-71.

McGettigan P, Henry D. 2006. Cardiovascular risk and inhibition of cyclo-oxygenase. A systematic review of the observational studies of selective and nonselective inhibitors of cyclooxygenase 2. JAMA, 296:1633-44.

Nussmeier NA, Whelton AA, Brown MT, et al. 2005. Complications of the COX-2 inhibitors parecoxib and valdecoxib after cardiac surgery. v New Engl J Med, 352:1081-91.

Ofman JJ, MacLean CH, Straus WL, et al. 2002. Meta-analysis of severe upper gastrointestinal complications of nonsteroidal antiinflammatory drugs. J Rheumatol, 29:804-12.

Rordorf C, Kellett N, Mair S, et al. 2003a. Gastroduodenal tolerability of lumiracoxib versus placebo and naproxen: a pilot endoscopic study in healthy male subjects. Aliment Pharmacol Ther, 18:533-41.

Rordorf C, Kellett N, Mair S, et al. 2003b. Gastroduodenal tolerability of lumiracoxib vs placebo and naproxen: a pilot endoscopic study in healthy male subjects. Aliment Pharmacol Ther, 18:533-41.

Schnitzer TJ, Burmester GR, Mysler E, et al; TARGET Study Group. 2004. Comparison of lumiracoxib with naproxen and ibuprofen in the Therapeutic Arthritis Research and Gastrointestinal Event Trial (TARGET), reduction in ulcer complications: randomised controlled trial. Lancet, 364:665-74.

Schnitzer TJ. 2006. Update on guidelines for the treatment of chronic musculoskeletal pain. Clin Rheumatol, 25(Suppl 1):S22-9.

Silverstein FE, Faich G, Goldstein JL, et al. 2000. Gastrointestinal toxicity with celecoxib vs nonsteroidal anti-inflammatory drugs for osteoarthritis and rheumatoid arthritis: the CLASS study: A randomized controlled trial. Celecoxib Long-term Arthritis Safety Study. JAMA, 284:1247-55.

Singh G. 1988. Recent considerations in nonsteroidal anti-inflammatory drug gastropathy. Am J Med, 105:31S-8S.

Solomon DH. 2005. Selective cyclo-oxygenase 2 inhibitors and cardiovascular events. Arthritis Rheum, 52:1968-78.

Solomon SD, McMurray JJ, Pfeffer MA, et al, for the Adenoma Prevention with Celecoxib (APC) Study Investigators. 2005. Cardiovascular risk associated with celecoxib in a clinical trial for colorectal adenoma prevention. $N$ Engl J Med, 352:1071-80.

Vane JR, Mitchell JA, Appleton I, et al. 1994. Inducible isoforms of cyclooxygenase and nitric-oxide synthase in inflammation. Proc Natl Acad Sci USA, 91:2046-50.

Vonkeman HE, Brouwers JRBJ, van de Laar MAFJ. 2006. Understanding the NSAID related risk of vascular events. $B M J, 332: 895-8$.

Warner TD, Giuliano F, Vojnovic I, et al. 1999. Nonsteroid drug selectivities for cyclo-oxygenase-1 rather than cyclo-oxygenase-2 are associated with human gastrointestinal toxicity: a full in vitro analysis. Proc Natl Acad Sci USA, 96:7563-8.

Wolfe MM, Lichtenstein DR, Singh G. 1999. Gastrointestinal toxicity of nonsteroidal antiinflammatory drugs. $N$ Engl J Med, 340:1888-99.

Zhang J, Ding EL, Song Y. 2006. Adverse effects of cyclooxygenase 2 inhibitors on renal and arrhytmia events. JAMA, 296:1619-32. 